\title{
La deriva del congreso regional o el congreso regional a la deriva
}

\author{
"Puedo escribir y no disimular \\ es la ventaja de irse haciendo viejo". \\ Adolfo Cabrales
}

Sr. Editor:

No he sido de los que se muerden la lengua, y sin embargo hay muchos temas que he procurado evitar por cortesía o simplemente por evitar situaciones incómodas. Sin embargo ésta no es necesariamente siempre la mejor opción. Así lo considero en este momento, y por eso quiero plantear una serie de cuestiones acerca del congreso regional de atención primaria.

Vaya por delante mi respeto a los puntos de vista que no coinciden con el mío. Mi objetivo no es, por supuesto, menospreciar a nadie. Sé lo que cuesta poner en marcha un congreso, y ese esfuerzo merece ya de entrada todo mi reconocimiento. Sólo deseo explicar mi opinión sin limitaciones dictadas por la cortesía o la prudencia.

Muchos de los socios fundadores de la Sociedad Castellano-Manchega de Medicina de Familia y Comunitaria (ahora SCAMFYC), y organizadores de las primeras ediciones de las jornadas de la sociedad, concebíamos éstas como un foro en el que presentar la actividad investigadora de los equipos de atención primaria, intentando precisamente fomentarla. En su sexta edición, en la que asumí la responsabilidad de presidir el comité organizador, se hizo patente la dificultad de asegurar su continuidad, toda vez que resultaba muy difícil conseguir el apoyo económico de la industria farmacéutica en competencia con otras sociedades de atención primaria con las que mantenían relaciones muchísimo más fluidas.

No me arrepiento de haber sido impulsor de la unificación organizativa con SEMERGEN. Al contrario, estoy muy satisfecho del camino recorrido hasta aquí, a pesar de las muchas diferencias de criterio. Sin embargo considero que la evolución del modelo de congreso ha ido progresivamente alejándose de los estándares que en su día defendió SCAMFYC. Así, hemos visto cómo los simposios de los laboratorios se han ido abriendo sitio, cómo los talleres han copado el tiempo del congreso, cómo los casos clínicos han ido invadiendo el espacio de las comunicaciones, y cómo los temas de las ponencias han ido adquiriendo un carácter cada vez más alejado de lo que podríamos llamar el perfil bio-psico-social del médico de familia. Durante el congreso hablé de un sesgo biologicista, pero éste no es sino un eufemismo para evitar hablar de exclusividad.

En este sentido creo que el congreso de Toledo ha marcado un nivel que debe hacernos reflexionar: 3 simposios de laboratorios farmacéuticos, 5 talleres (3 patrocinados por ellos) y las ponencias concentradas en temas tan manidos, como campo de batalla de la industria farmacéutica en su afán por extender sus negocios.

Se ha argumentado que si queremos tener financiación de la industria farmacéutica hay que plegarse a sus condiciones, y ya nadie parece poner en tela de juicio la celebración de simposios. Yo propongo que busquemos alternativas, empezando por reducir costes (la cena de gala podría sustituirse por un acto festivo mucho menos costoso, por poner un ejemplo).

¿Y las comunicaciones? Pues, si no tenemos en cuenta la masiva aportación de casos clínicos, hemos repuntado sobre las escasas aportaciones de años anteriores. En este sentido habría que felicitarse, aunque probablemente estemos fundamentalmente ante un fenómeno de ciudad, que también se da cuando la sede es Cuenca, y que actúa en sentido inverso en las otras ciudades, por razones de atractivo de unas y otras que actúa como reclamo de asistencia al congreso.

El análisis de las comunicaciones que entran en el congreso nos lleva a un aspecto si cabe más polémico, que es el del comité científico. Siempre he pensado, aunque no lo haya expresado más allá de pequeños círculos, que se trata de una labor eminentemente técnica que requiere el concurso de expertos. Entiendo por tales aquellos con formación específica en metodología de la investigación y con experiencia personal en la misma, que debería ir avalada por publicaciones en revistas de cierto nivel (y no estoy hablando precisamente de impacto). De forma que las cuotas no me parecen bien. $Y$ sin embargo nuestro comité científico está atado a ellas en una doble vertiente: por provincia (últimamente con doble representación para la provincia organizadora) y por sociedad científica. La concepción inicial del trabajo del comité científico, 
que permitía un debate en profundidad de las diferentes comunicaciones, también se ha ido perdiendo. En este sentido, este año hemos experimentado un cambio en la sistemática de trabajo, con una parcelación de la actividad del comité que, en mi opinión, ha supuesto una falta de homogeneidad en la selección de las comunicaciones.

Sé que algunos de los que hayan tenido ánimo para seguir leyendo hasta aquí estarán pensando que hablo desde el resentimiento. Aquellos con quienes he coincidido en varios comités saben de mis vehementes diatribas a favor o en contra de ciertas comunicaciones. Y es que es difícil admitir el "sesgo de publicación" que se permite un comité científico que pasa por alto problemas metodológicos de calado y sin embargo menosprecia, o directamente rechaza, trabajos en base a razones relacionadas con la elección del tema o el desacuerdo personal con los resultados, a pesar de estar realizados desde la más absoluta pulcritud metodológica, o incluso suponen incursiones en campos poco explorados en nuestro medio como la investigación cualitativa o las actividades comunitarias.

Este año se ha producido una situación muy llamativa: se presentaron al congreso 9 trabajos de Albacete, de los que 6 eran casos clínicos. De las 3 comunicaciones de investigación 2 iban firmadas (entre otros) por mí, y ninguna de ellas fue aceptada. De forma que sí, algo de resentimiento debe haber.

Francisco Escobar Rabadán Médico de Familia del Centro de Salud Universitario Zona IV de Albacete

Profesor Asociado de la Facultad de Medicina de Albacete C/ Seminario, 4 02006 - Albacete fjescobarr@sescam.jccm.e 